\title{
PAPER
}

\section{Impact of thalamic deep brain stimulation on disability and health-related quality of life in patients with essential tremor}

\author{
G-M Hariz, M Lindberg, A T Bergenheim
}

J Neurol Neurosurg Psychiatry 2002;72:47-52

See end of article for authors' affiliations

......................

Correspondence to: Dr A T Bergenheim, Department of Clinical

Neurosciences, University

Hospital, S-901 85 Umeå,

Sweden;

tommy.bergenheim@

neuro.umu.se

Received

27 November 2000

In revised form 1 June

2001

Accepted 18 July 2001
Objectives: To evaluate the impact of thalamic deep brain stimulation (DBS) on disability and healthrelated quality of life in patients with essential tremor.

Methods: Twenty seven consecutive patients were evaluated prospectively, before surgery and at a mean of 12 months (range 6-26) after thalamic DBS. Assessment tools included the Fahn-Tolosa-Marìn tremor rating scale (TRS), activities of daily living (ADL) taxonomy, Nottingham health profile (NHP) and the visual analogue scale (VAS) for measuring impact of disease on life. Additional information on the side effects of, and expectations from surgery was obtained by interview.

Results: Thalamic DBS improved the ability of the patients in eating, drinking, writing, home maintenance, hobbies, and participation in society. Activities of daily life requiring bimanual skills were less improved. The emotional condition of the patients was positively affected and the negative impact of the disease on life as a whole, and on social life was decreased. Seventy per cent of the patients considered that the surgical treatment met their expectations.

Conclusions: After thalamic DBS, health-related quality of life including disability in ADL and social life were improved in patients with essential tremor.
E ssential tremor may, in an advanced state of the disease, have a negative impact on daily life and restrict participation in society, thus affecting the patient's health-related quality of life. ${ }^{1-6}$ Deep brain stimulation (DBS) of the thalamic ventral intermedius nucleus (Vim) has become an established method for surgical treatment of medically resistent essential tremor. $^{7-12}$ The positive effect of Vim DBS on essential tremor has been documented mainly on the level of impairmentthat is, the effect on tremor. ${ }^{8-11}{ }^{13-15}$ However, the impact of thalamic DBS on disability and health-related quality of life of patients with essential tremor has so far only been marginally addressed. ${ }^{612} 1617$

Health-related quality of life (HRQOL) as defined by Shumaker and Naughton ${ }^{18}$ "refers to people's subjective evaluations of the influences of their current health-status, health care, and health promoting activities on their ability to achieve and maintain a level of overall functioning that allows them to pursue valued life goals, and that is reflected in their general well-being. The domains of functioning that are critical to HRQOL, include: social, physical and cognitive functioning; mobility and self-care; and emotional well-being" (p 7).

The aim of this study was to evaluate ability and disability in daily life and other aspects of HRQOL in patients with essential tremor treated with thalamic DBS.

\section{MATERIALS AND METHODS \\ Patients}

Twenty eight consecutive patients scheduled for thalamic DBS entered the prospective study. One male patient was excluded, when after 3 days of unsuccessful trial stimulation, his electrode was explanted. The remaining 27 patients (nine women) completed the study. All patients had a diagnosis of essential tremor and were referred for surgery by neurologists, after failure of pharmacological treatment. The age at surgery was 66 (SD 11) years (range 25-79 years) and the duration of tremor was 21 (SD 19) years (range $2-56$ years). In 23 patients surgery was performed for tremor of their dominant hand.
Table 1 Demographic and clinical characteristics of 27 patients with essential tremor undergoing chronic thalamic deep brain stimulation

\begin{tabular}{lll}
\hline Age (mean (SD; range)) & 66.1 & $(11.0 ; 25-79)$ \\
Sex (female/male) & $9 / 18$ & \\
Duration of disease (y) (mean (SD; range)) & 21.0 & $(18.6 ; 2-56)$ \\
Unilateral tremor (n (\%)) & 6 & $(22.2)$ \\
Bilateral tremor (n (\%)) & 21 & $(77.8)$ \\
Surgery for dominant hand (n (\%)) & 23 & $(85)$ \\
Living alone (n (\%)) & 13 & $(48)$ \\
Living with spouse (n (\%)) & 14 & $(52)$ \\
Professionally active no (\%) & 4 & $(15)$ \\
$\begin{array}{c}\text { MMSE total score preoperative } \\
\quad \text { (mean (SD; range))* }\end{array}$ & 26.6 & $(2.5 ; 21-30)$ \\
\hline
\end{tabular}

* Items 19 and 20 (writing and drawing) of the MMSE were not feasible due to severe tremor in $13(48 \%)$ patients.

Table 1 shows the demographic, social, and clinical characteristics as well as the mini mental state examination (MMSE) score of the patients. Four patients had previously been operated on with Vim thalamotomy (in two patients ipsilateral to the current Vim DBS). One patient had previously been operated on with Vim thalamotomy and, later on, Vim DBS, both contralateral to the present DBS.

The patients gave their informed consent to participation in this study, which was part of a comprehensive programme for evaluation of functional neurosurgical procedures at our institution.

Abbreviations: DBS, deep brain stimulation; TRS, tremor rating scale; ADL, activities of daily living; NHP, Nottingham health profile; VAS, visual analogue scale; Vim, ventral intermedius nucleus; HRQOL, health related quality of life; MMSE, mini mental state examination 
All patients were operated on using CT and/or MRI guided target coordinates and the Laitinen stereotactic system. During surgery, impedance recording and macrostimulation confirmed the physiological target. A quadripolar Medtronic 3387 electrode (Minneapolis, USA) and a Medtronic ITREL II neurostimulator were implanted.

\section{Evaluation procedures}

The patients were interviewed and examined by, G-M H 1 to 3 days before surgery, and 12.5 (SD 4.7) months (range 6-26 months) after surgery. When the postoperative evaluation was performed, neither patient nor evaluator had access to the results of the preoperative evaluation. The following assessment tools were used:

\section{Tremor rating scale (TRS)}

The Fahn-Tolosa-Marìn tremor rating scale (TRS) ${ }^{19}$ is a widely used instrument. ${ }^{10}$ It rates severity of tremor from zero (none) to four (severe). The scale is divided into three parts. Part A (with a maximum score of 80 ) quantifies tremor at rest, during posture, and intentional manoeuvres for nine parts of the body. Part B (with a maximum score of 36) rates action tremor of the upper limbs, particularly while writing and pouring liquids. In part $\mathrm{C}$ the patient rates the impact of tremor on his or her functional disability (speaking, feeding, drinking, hygiene, dressing, writing, and working) with a maximum score of 28 . The total score obtained by adding the three parts of the TRS is 144. Finally, the TRS includes one separate item dealing with global assessment of tremor related disability, rated by both patient and examiner on a 5 point scale.

\section{Mini mental state examination (MMSE)}

The MMSE is a brief cognitive test widely used for screening of dementia. ${ }^{20}$ It is a standardised 30 point scale that encompasses different aspects of cognition, assessed within 20 items. A score of 23 represents a cut off score for suspected dementia. $^{21}$

\section{ADL taxonomy scale}

The ADL taxonomy scale is an occupational therapy scale focusing on activities of daily life (ADL). ${ }^{22}$ It includes 12 different activities common to most persons, dealing with self maintenance. Seven activities may be defined as personal ADL (eating/drinking, mobility, going to the toilet, dressing, personal hygiene, grooming, and communication). Five activities belong to instrumental ADL-that is, household activities (cooking, shopping, cleaning, washing, and transportation). Each activity comprises a sequence of actions. For example, the activity eating/drinking consists of three actions as follows: ( 1 ) eating - that is, bringing food from a plate into the mouth and eating; (2) drinking - that is, bringing liquid from a glass into the mouth and drinking; (3) eating and drinking and cutting up and preparing food. The number of action items within an activity varies from two to six. The actions within each activity are assumed to be hierarchically organised from the easiest to the more demanding one. Especially for this study, the following amplification to the ADL taxonomy has been performed: To each action a five point scale has been assigned, from one to five: $1=$ perform the action independently and without difficulty; $2=$ perform the action independently but with some effort; $3=$ perform the action independently but with major effort; $4=$ perform the action with some help from an assistant, - that is, partly dependent; and $5=$ cannot perform the action at all-that is, totally dependent. The patients rated those actions that they considered relevant for them as described above. The results of this five point scale were also grouped into the following levels of performance: no problem in performing the ADL action (point 1); perform ADL action with effort (points 2 and 3); and dependent on another person when performing the ADL action (points 4 and 5 ).

\section{Nottingham health profile (NHP)}

The NHP is a generic self assessed measure of perceived distress, reflecting health status. ${ }^{23}{ }^{24}$ It consists of two parts: part I includes the fundamentals of the NHP covering the following six dimensions: emotional reactions, sleep, energy level, pain, physical mobility, and social isolation. The patient answers "yes" or "no" to 38 statements. The statements included in each area are weighted according to perceived severity. Zero indicates no problem and 100 indicates maximal distress. These six dimensions provide together a health profile. Part II of the NHP evaluates seven domains of daily life that can be affected by disease: occupation, household management, social life, family life, sex life, hobbies/interests, and holidays. Each area is evaluated using one statement with the alternatives "yes" or "no". As only four of our patients were professionally active before surgery, the item of NHP II related to occupation was not considered in this study.

\section{Visual analogue scale}

A $100 \mathrm{~mm}$ long horizontal visual analogue scale (VAS) ${ }^{25}$ was used to evaluate the impact of the disease on life as a whole and on social life. The following two questions were presented to the patients: (1) "Consider all aspects in which your tremor disease affects you and put a mark on the line that describes your total life situation"; (2) "Consider all aspects in which your tremor disease affects your social life and indicate that by a mark on the line". The patients were instructed that $0 \mathrm{~mm}$ indicated no impact at all and $100 \mathrm{~mm}$ indicated the most severe impact.

\section{Additional questions}

Postoperatively the patients were asked two questions: "Have you perceived any negative effects that you associate with the surgery or the stimulation?" and "How did deep brain stimulation meet your expectations on the treatment of your tremor disease?"

For statistical analysis, Wilcoxon's signed rank test for paired samples was used. The level of significance was chosen at $\mathrm{p}<0.05$.

\section{RESULTS}

The effect of chronic DBS, rated on the TRS, is shown in figure 1: Total scores of TRS improved by $47 \%$. Part A improved by $53 \%$, part B by $39 \%$, and part C by $54 \%$. The items of the TRS part A, dealing specifically with upper limb tremor contralateral to DBS, scored 7 (out of a maximum score of 12) preoperatively, and 1.5 postoperatively (79\% improvement,

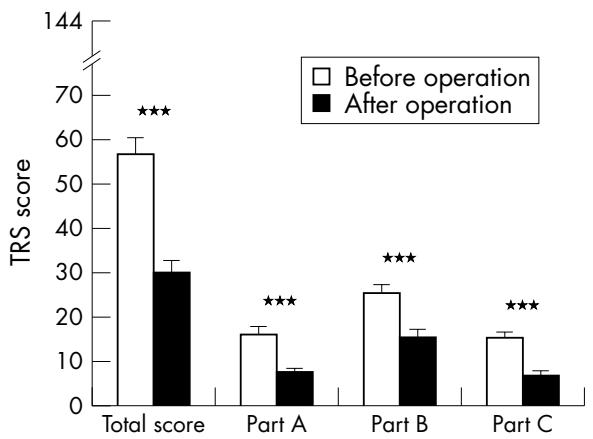

Figure 1 Preoperative and postoperative scores of the Fahn-Tolosa-Marín tremor rating scale (TRS) in 27 patients with essential tremor treated with thalamic DBS. Total mean score (SEM), as well as scores from the three subscales of TRS are shown. $* * * p<0.0001$ 
A

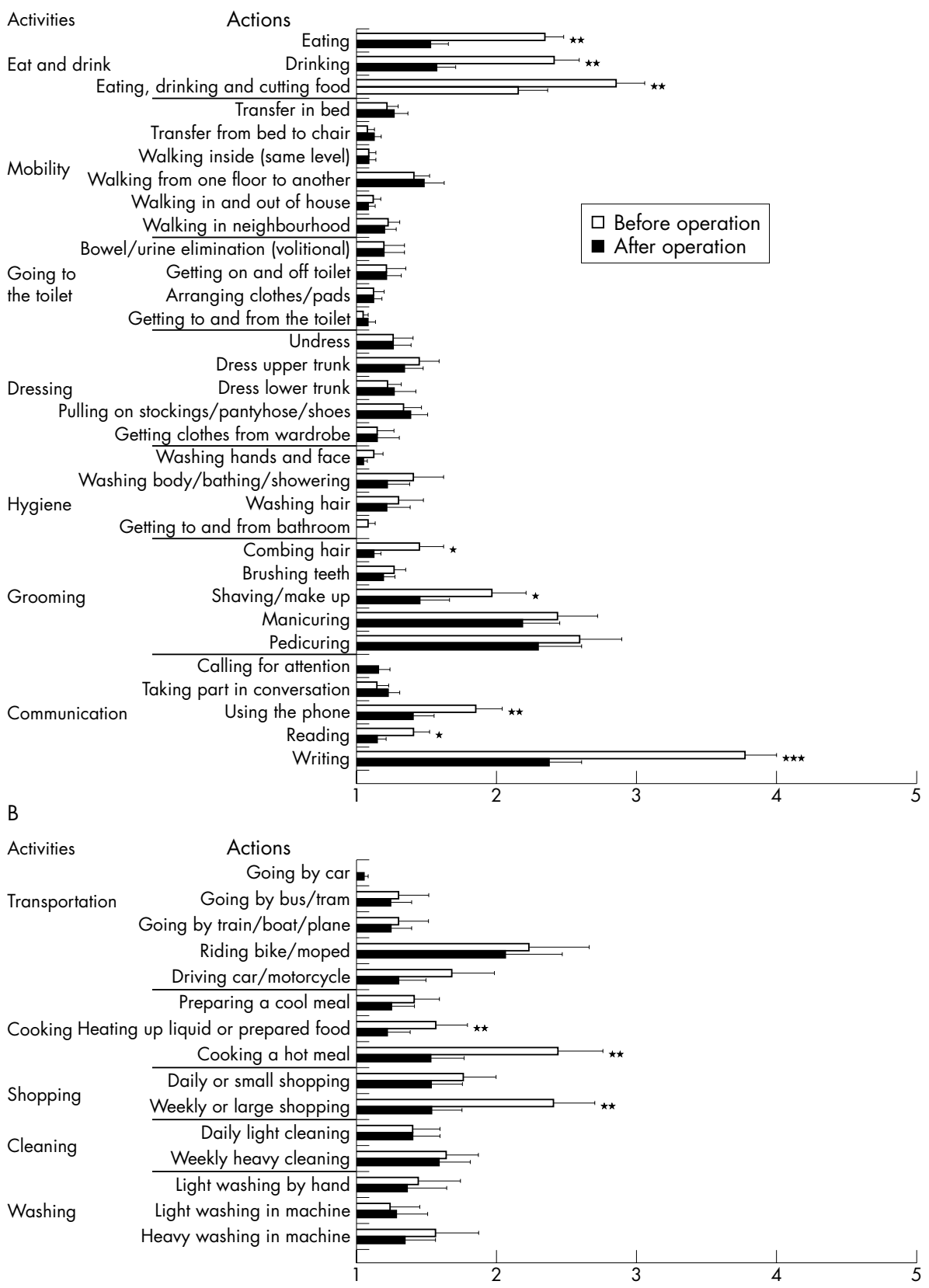

Figure 2 Results from the ADL taxonomy for personal $A D L(A)$ and instrumental $A D L$. (B) The bar graphs show preoperative and postoperative mean (SEM) values. $1=$ Perform the action independently and without problems; $2=$ perform the action independently but with some effort; 3 =perform the action independently but with major effort; $4=$ perform the action with some help from an assistant-that is, partly dependent; and $5=$ cannot perform the action at all-that is, is totally dependent. ${ }^{*} p<0.05 ;{ }^{* *} p<0.01 ;{ }^{* \star *} p<0.0001$.

$\mathrm{p}<0.001)$. The score of items of part B dealing with contralateral drawing and pouring tasks (with a maximum score of 16) decreased from 12.6 preoperatively to 4.8 postoperatively $(62 \%$ improvement, $\mathrm{p}<0.001)$. The score of the separate TRS item dealing with global assessment of functional disability decreased from 2.6 to $1.6(\mathrm{p}<0.001)$ as assessed by the patients, and from 1.8 to $1.2(\mathrm{p}<0.01)$ as assessed by the examiner.

The mean total score of the MMSE did not change after surgery. Preoperatively it was 26.6 (SEM 0.5); range 21-30 and postoperatively it was 27.4 (SEM 0.5); range 21-30. Items 19 and 20 of the MMSE (writing a sentence and copying a figure) were not feasible due to severe tremor in $13(48 \%)$ patients preoperatively and in five (18\%) postoperatively.
The results according to the ADL taxonomy are described in figure $2 \mathrm{~A}$ and $\mathrm{B}$. Table 2 shows the distribution of patients in the three levels of performance with respect to those actions of the ADL taxonomy that showed statistically significant changes after DBS.

In table 3 the results according to the NHP are presented: NHP I showed a significant improvement in emotional reactions and NHP II in household management, social life, and interests/hobbies.

Evaluations according to the VAS gave the following results: The impact of tremor on "life as a whole" was 70.5 (SEM 4.1) $\mathrm{mm}$; range 26-100 before surgery and 39.2 (SEM 5.0) mm; range 0-97 postoperatively, $(\mathrm{p}<0.0001)$. The impact of tremor on "social life" was 62.5 (SEM 5.9) mm; range 0-100 
Table 2 Results from those actions of the ADL taxonomy that showed statistically significant changes after DBS, tricotomised into different levels of performance

\begin{tabular}{|c|c|c|c|c|}
\hline \multirow[b]{2}{*}{ Type of ADL action } & \multirow[b]{2}{*}{$\begin{array}{l}\text { Operative } \\
\text { stage }\end{array}$} & \multicolumn{3}{|c|}{$\begin{array}{l}\text { No of patients in each of the three levels of } \\
\text { performance }\end{array}$} \\
\hline & & $\begin{array}{l}\text { Without problem } \\
\text { when performing } \\
\text { ADL action }\end{array}$ & $\begin{array}{l}\text { Perform ADL } \\
\text { action with effort }\end{array}$ & $\begin{array}{l}\text { Dependent on } \\
\text { other person } \\
\text { when performing } \\
\text { ADL action }\end{array}$ \\
\hline \multirow[t]{2}{*}{ Eating } & Preop & 1 & 24 & 2 \\
\hline & Postop & 15 & 12 & 0 \\
\hline \multirow[t]{2}{*}{ Drinking } & Preop & 3 & 20 & 4 \\
\hline & Postop & 16 & 11 & 0 \\
\hline \multirow[t]{2}{*}{ Eating/drinking cut food } & Preop & 1 & 18 & 8 \\
\hline & Postop & 9 & 11 & 7 \\
\hline \multirow[t]{2}{*}{ Combing hair } & Preop & 19 & 7 & 1 \\
\hline & Postop & 24 & 3 & 0 \\
\hline \multirow[t]{2}{*}{ Shaving/make up } & Preop & 13 & 11 & 3 \\
\hline & Postop & 22 & 3 & 2 \\
\hline \multirow[t]{2}{*}{ Using telephone } & Preop & 11 & 14 & 2 \\
\hline & Postop & 19 & 7 & 1 \\
\hline \multirow[t]{2}{*}{ Reading } & Preop & 17 & 10 & 0 \\
\hline & Postop & 23 & 4 & 0 \\
\hline \multirow[t]{2}{*}{ Writing } & Preop & 0 & 13 & 14 \\
\hline & Postop & 7 & 16 & 4 \\
\hline \multirow[t]{2}{*}{ Heating up liquid/preparing food* } & Preop & 17 & 6 & 2 \\
\hline & Postop & 23 & 1 & 1 \\
\hline \multirow[t]{2}{*}{ Cooking a hot meal* } & Preop & 9 & 10 & 6 \\
\hline & Postop & 20 & 3 & 2 \\
\hline \multirow[t]{2}{*}{ Weekly shopping* } & Preop & 10 & 9 & 6 \\
\hline & Postop & 19 & 3 & 3 \\
\hline
\end{tabular}

preoperatively and 26.2 (SEM 5.8) mm; range 0-99 after surgery, $(\mathrm{p}<0.001)$.

The following adverse effects were reported postoperatively: Deterioration of balance in two patients (one of whom had had a previous ipsilateral thalamotomy); negative influence on speech in three patients (two of whom had had contralateral thalamotomy); and deterioration of both speech and balance in two patients (one of whom had had a contralateral thalamotomy then a contralateral DBS). Four patients reported that tremor on the non-operated side had become notably worse after surgery. One thin patient felt discomfort from the bulging of the neurostimulator in the infraclavicular area. One patient reported tiredness, one became tearful, and

Table 3 NHP part I and NHP part II before and after thalamic deep brain stimulation for essential tremor.

\begin{tabular}{|c|c|c|}
\hline & $\begin{array}{l}\text { Preoperative } \\
\text { mean (SEM) }\end{array}$ & $\begin{array}{l}\text { Postoperative } \\
\text { mean (SEM) }\end{array}$ \\
\hline \multicolumn{3}{|l|}{ NHP I: } \\
\hline Emotional reactions & $12.3(3.4)$ & $7.1(2.9)^{* *}$ \\
\hline Sleep & $21.4(4.6)$ & $16.1(2.8)$ \\
\hline Energy & $16.3(5.9)$ & $20.8(6.0)$ \\
\hline Pain & $14.3(3.5)$ & $14.8(3.9)$ \\
\hline Physical mobility & $13.1(3.8)$ & 17.7 (3.9) \\
\hline Social isolation & $9.4(3.2)$ & $7.4(3.8)$ \\
\hline NHP II: & $\%$ & $\%$ \\
\hline Looking after the home & 70.4 & $44.4^{* *}$ \\
\hline Social life & 74.0 & $29.6 * * *$ \\
\hline Family life & 3.7 & 7.7 \\
\hline Sex lifet & 14.3 & 20.0 \\
\hline Interests/hobbies & 77.8 & $44.4^{*}$ \\
\hline Holidays & 34.6 & 23.1 \\
\hline \multicolumn{3}{|c|}{$\begin{array}{l}{ }^{*} p<0.05 ;{ }^{*} p<0.01 ;{ }^{*}{ }^{*} p<0.001 ; \text { this domain was answered } \\
\text { preoperatively by } 21 \text { patients and postoperatively by } 20 \text { patients. The } \\
\text { figures of NHP I are the mean scores (SEM); the figures of NHP II } \\
\text { show the percentage of patients who expressed difficulty in each } \\
\text { domain }\end{array}$} \\
\hline
\end{tabular}

one complained of headache. Fourteen patients (52\%) did not report any adverse effect. To the question whether thalamic DBS met the patients' expectations, 19 patients $(70.4 \%)$ answered yes, six (22.2\%) answered partially, and two $(7.4 \%)$ answered no.

\section{DISCUSSION}

The primary aim of this study was to evaluate in patients with essential tremor the impact of chronic thalamic DBS on ADL and aspects of HRQOL. We found that thalamic DBS contributed to an improvement in several of the preoperatively demanding activities of daily life, such as eating, drinking, writing, cooking a meal, and shopping. Several patients who preoperatively were dependent in performing some of the daily activities became independent after surgery. There was also a decrease of negative emotions and an improvement of the social life of the patients and of their ability to maintain interests and hobbies.

\section{Assessment tools}

Because our main focus was to assess the impact of thalamic DBS on disability and HRQOL, we tried to perform a comprehensive evaluation of various domains and aspects of daily life activities and HRQOL. For this we used the following assessment tools: the TRS, the ADL taxonomy, NHP, and the VAS. The TRS of Fahn, Tolosa and Marìn ${ }^{19}$ has been validated, to the best of our knowledge, only for tremor in multiple sclerosis. ${ }^{26}$ However, it has been extensively used for evaluation of thalamic DBS for tremor, notably in two recent large multicentre studies, one North American" and one European. ${ }^{10}$ The ADL taxonomy and the NHP are both generic scales that are validated for use in a Swedish population. ${ }^{22}{ }^{27}$ The VAS was primarily developed for rating various clinical and social aspects in individual patients. ${ }^{28}$ It has also been used in measurement of wellbeing, ${ }^{29}$ for evaluation of pallidotomy results in parkinsonian patients, ${ }^{30}$ and for measuring ADL in patients with essential tremor. ${ }^{31}$

Most of these evaluation instruments are based on the patient's own, subjective perception of his or her situation, 
which is a fundamental in measuring health-related quality of life. $^{1832}$ The evaluations were conducted in the same way before and at a mean of 1 year after surgery. Hence, the patients acted as their own control after surgery. We were aware that some dimensions in the used scales overlapped to some extent. However, the fact that different tools evaluated the same or related aspects of life, and generally provided similar answers, contributed to the corroboration of our results.

\section{Results on tremor and implications for ADL}

In agreement with other reports, thalamic DBS for essential tremor had a good effect on tremor. ${ }^{910^{12}{ }^{15}}$ The scores of the TRS part A (tremor) and part C (functional disability) decreased markedly after surgery. By assessing the patients with the ADL taxonomy scale, we could outline which daily activities were difficult to perform before surgery and what impact Vim DBS had on each of the daily activities of the patients (fig 2 A and B, and table 2). We showed that Vim DBS had a positive and clinically relevant effect on those activities of daily life that were problematic for the patients before surgery, such as eating, drinking, writing, cooking, and shopping.

Eating and drinking are important and frequent activities not only for nutritive purposes, but also for social contacts. Inability to eat and drink in a socially accepted manner may stress the patients and prevent those with tremor from contacts, and thereby the patient may become isolated..$^{2-43}$ Cutting food still remained difficult to perform after surgery, probably because this activity requires bimanual skills whereas most of our patients had surgery for one side of the body only.

Writing was preoperatively the most affected action among all daily activities: all patients had difficulties when writing and more than half of them needed some personal assistance or were totally unable to write. After surgery $26 \%$ of the patients had gained the ability to write without any difficulty.

Cooking a hot meal was preoperatively a demanding action. Apart from the risk of spilling, the patients were at risk of burning themselves when preparing food. After surgery, $80 \%$ of the patients were able to cook a hot meal without effort compared with $36 \%$ before surgery.

Weekly shopping was for many patients an action that required effort preoperatively, probably due to the stressful environment and to the need for handling coins or credit cards where signing receipts is sometimes requested. Thalamic DBS improved the patients in this activity.

Although not considered as very demanding tasks preoperatively, the actions "shaving/make up", "combing one's hair", "using a phone" and "reading" did improve after surgery. All these activities have an impact on communication and social life. On the other hand, there were several activities that preoperatively were not demanding and that were not affected by thalamic DBS: These activities concerned mobility, going to the toilet, dressing, hygiene, cleaning the house, and washing clothes (fig $2 \mathrm{~A}$ and $\mathrm{B}$ ).

The use of the ADL taxonomy allowed us also to distinguish those actions that were difficult to perform before surgery but that did not improve after surgery, such as manicuring and pedicuring. These actions require bimanual coordination, and most patients still had tremor affecting the non-operated hand. However, as manicure and pedicure are more easily planned and not very often performed compared with other ADL activities, the overall impact of these actions on disability in the patients as a group may be limited.

\section{Influence of thalamic DBS on other aspects of HRQOL}

The results from the six dimensions of NHP (part I) showed improvement only in the patients' emotional constraint after surgery. A positive impact of Vim DBS on emotions in patients with essential tremor was also reported by Tröster $e t a l^{17}$ who used a modified version of the Parkinson's disease questionnaire (PDQ-39). Other items of NHP I did not disclose changes between preoperative and postoperative status of the patients. The reason for this may be that these items of the NHP represent rather severe difficulties and are not sensitive enough to detect health-related problems in patients with disability related to a single disabling symptom. ${ }^{23}{ }^{24}$ The second part of the NHP, evaluating six areas of daily life that can be affected by disease, showed that thalamic DBS had a positive impact on home maintenance, social life, and interests/hobbies. These findings corroborated our results from the ADL taxonomy scale. Family life, sex life, and holidays did not change after surgery. The VAS confirmed that the negative impact of essential tremor on the patients' life as whole and on their social life was less prominent after surgery than before. One advantage of using a visual analogue scale, apart from its briefness, is that it is the patient's own subjective definition of "life as a whole" and of "social life" that determines the answer.

Both patients and examiner scored a positive outcome according to the item of TRS dealing with "global assessment of tremor related disability". However, the patients attributed to themselves worse scores than the scoring attributed to them by the examiner preoperatively. Additionally, the patients expressed more gain after treatment than the examiner did. These results highlight the discrepancy between patient and examiner in perception of the impact of disease on life. This discrepancy illustrates the subjective character of health related aspects of life, and the importance in considering this subjective dimension when evaluating surgical treatment for patients with essential tremor.

\section{Expectations from surgery and side effects}

Seventy per cent of our patients considered that thalamic DBS fulfilled their expectations. Although this may be considered as a positive result, it does not in itself provide information on the level of expectations: expectations might in some patients be set at a low level such as "hopefully DBS will not harm me " or at a very high level such as "I am going to be cured by DBS".

Roughly half of the patients did to some degree experience some negative phenomenon that they associated with the DBS. Some of these side effects, such as deterioration of speech and balance are well known and previously described after DBS surgery, especially in those patients who had had a previous contralateral thalamic procedure. ${ }^{7112} 15{ }^{34}$ Among the seven patients who experienced side effects on speech or balance, three reported that their expectations from treatment were fulfilled and four considerd their expectations only partially fulfilled. Four patients experienced a worsening of tremor on the side ipsilateral to stimulation. However, in a previous study, we showed that when assessed with TRS, the ipsilateral tremor did not significantly increase after Vim DBS. ${ }^{11}$ It may be that some patients resented the tremor ipsilateral to DBS more, when the contralateral tremor had been alleviated.

\section{CONCLUSIONS}

In patients with essential tremor Vim DBS contributed to an improvement in several of the preoperatively demanding activities of daily life, such as eating, drinking, writing, cooking a meal, and shopping. Some patients who preoperatively were dependent in performing daily activities became independent after surgery. Concordant information provided by various assessment tools showed that Vim DBS contributed to a decrease in emotional constraints and an improvement of other aspects of health related quality of life, including participation in social life and in hobbies and interests. These effects of Vim DBS, assessed at a mean of 1 year after surgery, need to be confirmed over a longer term. 


\section{ACKNOWLEDGEMENTS}

This study was supported by the VÅRDAL foundation, the Swedish Association of the Neurologically Disabled (NHR), and the Research Foundation of the Department of Clinical Neurosciences at the University Hospital of Northern Sweden.

\section{Authors' affiliations}

G-M Hariz, A T Bergenheim, Department of Clinical Neurosciences, University Hospital of Northern Sweden, Umeå, Sweden

M Lindberg, Department of Community Medicine and Rehabilitation, Section of Occupational Therapy, Umeå University, Sweden

\section{REFERENCES}

1 Larsson T, Siögren T. Essential tremor: a clinical and genetic population study. Acta Psychiatr Neurol Scand 1960;36(suppl 144):1-176.

2 Marshall J. Tremor. In: Vinken PJ, Bruyn GW, eds. Handbook of clinical neurology. Vol 6. Diseases of the basal ganglia. New York: American Elsevier Publishing, 1968:809-25.

3 Critchley E. Clinical manifestations of essential tremor. J Neurol Neurosurg Psychiatry 1972;35:365-72.

4 Koller W, Biary N, Cone S. Disability in essential tremor: effect of treatment. Neurology 1986;36:1001-4.

5 Busenbark KL, Nash J, Nash S, et al. Is essential tremor benign? Neurology 1991:41:1982-3.

6 Lyons KE, Pahwa R, Busenbark KL, et al. Improvements in daily functioning after deep brain stimulation of the thalamus for intractable tremor. Mov Disord 1998; 13:690-2.

7 Benabid AL, Pollak P, Gervason C, et al. Long-term suppression of tremor by chronic stimulation of the ventral intermediate thalamic nucleus. Lancet 1991;337:403-6.

8 Blond S, Caparros-Lefebvre D, Parker F, et al. Control of tremor and involuntary movement disorders by chronic stereotactic stimulation of the ventral intermediate thalamic nucleus. J Neurosurg 1992;77:62-8.

9 Koller W, Pahwa R, Busenbark K, et al. High-frequency unilateral thalamic stimulation in the treatment of essential and parkinsonian tremor. Ann Neurol 1997;42:292-9.

10 Limousin P, Speelman JD, Gielen F, et al. Multicentre European study of thalamic stimulation in parkinsonian and essential tremor. J Neurol Neurosurg Psychiatry 1999;66:289-96.

11 Hariz MI, Shamsgovara P, Johansson F, et al. Tolerance and tremor rebound following long-term chronic thalamic stimulation for parkinsonian and essential tremor. Stereotact Funct Neurosurg 1999;72:208-18.

12 Schuurman PR, Bosch DA, Bossuyt PMM, et al. A comparison of continuous thalamic stimulation and thalamotomy for suppression of severe tremor. N Engl J Med 2000;342:461-8.

13 Benabid AL, Pollak P, Seigneuret E, et al. Chronic VIM thalamic stimulation in Parkinson's disease, essential tremor and extra-pyramidal dyskinesias. Acta Neurochir Suppl (Wien) 1993;58:39-44.

14 Siegfried J. Therapeutic stereotactic procedures on the thalamus for motor movement disorders. Acta Neurochir (Wien) 1993;124:14-18.
15 Benabid AL, Pollak P, Gao D et al. Chronic electrical stimulation of the ventralis intermedius nucleus of the thalamus as a treatment of movement disorders. J Neurosurg 1996;84:203-14.

16 Hariz G-M, Bergenheim AT, Hariz Ml, et al. Assessment of ability/disability in patients treated with chronic thalamic stimulation for tremor. Mov Disord 1998;13:78-83.

17 Tröster Al, Fields JA, Pahwa R, et al. Neuropsychological and quality of life outcome after thalamic stimulation for essential tremor. Neurology 1999:53:1774-80.

18 Shumaker SA, Naughton M. The international assessment of healthrelated quality of life: a theoretical perspective. In: Shumaker SA, Berzon $R$, eds. The international assessment of health-related quality of life: theory, translation, measurement and analysis. Oxford: Rapid Communications of Oxford, 1995:3-10.

19 Fahn S, Tolosa E, Marín C. Clinical rating scale for tremor. In: Jankovic J, Tolosa E, eds. Parkinson's disease and movement disorders. Baltimore: Urban and Schwarzenberg, 1988:225-34.

20 Folstein MF, Folstein SE, McHugh PR. "Mini-mental state": a practical method for grading the cognitive state of patients for the clinician. $J$ Psychiatr Res 1975;12:189-98.

21 Fillenbaum G, Heyman A, Williams K, et al. Sensitivity and specificity of standardized screens of cognitive impairment and dementia among elderly black and white community residents. J Clin Epidemiol 1990;43:651-60.

22 Törnquist K, Sonn U. Towards an ADL taxonomy for occupational therapists. Scand J Occup Ther 1994;1:69-76.

23 Hunt SM, McEwen J, McKenna SP. Measuring health status: a new tool for clinicians and epidemiologists. J Coll Gen Pract 1985;35: 185-8.

24 Wiklund I. The Nottingham health profile: a measure of health-related quality of life. Scand J Prim Health Care Suppl 1990;1:15-8.

25 Huskisson EC. Measurement of pain. Lancet 1974;2(7889):1127-31.

26 Hooper J, Taylor R, Pentland B, et al. Rater reliability of Fahn's tremor rating scale in patients with multiple sclerosis. Arch Phys Med Rehabil 1998;79:1076-9.

27 Wiklund I, Romanus B, Hunt SM. Self-assessed disability in patients with arthrosis of the hip joint. Reliability of the Swedish version of the Nottingham health profile. International Disability Studies 1988; 10:159-63.

28 Freyd $M$. The graphic rating scale. Journal of Educational Psychology 1923;14:83-102.

29 Clarke PRF, Spear FG. Reliability and sensitivity in the self assessment of well being [abstract]. Bull Br Psychol Soc 1964;17:18A.

30 Favre J, Burchiel KJ, Taha JM, et al. Outcome of unilateral and bilatera pallidotomy for Parkinson's disease: patient assessment. Neurosurgery 2000;46:344-53.

31 Auff E, Doppelbauer A, Fertl E. Essential tremor: functional disability vs. subjective impairment. J Neural Transm Suppl 1991;33:105-10.

32 Meyers AR, Gage H, Hendricks A. Health-related quality of life in neurology. Arch Neurol 2000;57: 1224-7.

33 George MS, Lydiard RB. Social phobia secondary to physical disability. A review of benign essential tremor (BET) and stuttering. Psychosomatics 1994;35:520-3.

34 Pahwa R, Lyons KL, Wilkinson SB, et al. Bilateral thalamic stimulation for the treatment of essential tremor. Neurology 1999;53:1447-50. 